\title{
Contrasting effects of environmental factors during larval stage on morphological plasticity in post-metamorphic frogs
}

\author{
Miguel Tejedo ${ }^{1, *}$, Federico Marangoni ${ }^{1,2}{ }^{,}$Cino Pertoldi ${ }^{3}$, Alex Richter-Boix ${ }^{4}$, \\ Anssi Laurila ${ }^{4}$, Germán Orizaola ${ }^{4}$, Alfredo G. Nicieza ${ }^{5}$, David Álvarez ${ }^{5}$, \\ Iván Gomez-Mestre ${ }^{5,6}$
}

\footnotetext{
${ }^{1}$ Department of Evolutionary Ecology, Estación Biológica de Doñana, CSIC, Avda. Américo Vespucio s/n, 41092 Sevilla, Spain

${ }^{2}$ Laboratorio de Genética Evolutiva, FCEQyN-UnaM/CONICET, Félix de Azara 1552, 6to Piso 3300 Posadas - Misiones, Argentina

${ }^{3}$ Department of Ecology and Genetics, Institute of Biological Sciences, University of Aarhus, Denmark

${ }^{4}$ Department of Population Biology and Conservation Biology, Evolutionary Biology Centre (EBC), Uppsala University, Norbyvägen 18 D, 75236 Uppsala, Sweden

${ }^{5}$ Ecology Unit, Department of Biology of Organisms and Systems, University of Oviedo, 33071 Oviedo, and Cantabrian Institute of Biodiversity (ICAB), Spain

${ }^{6}$ Department of Wetland Ecology, Estación Biológica de Doñana, CSIC, Avda. Américo Vespucio s/n, 41092 Sevilla, Spain
}

\begin{abstract}
In organisms with complex life cycles, environmentally induced plasticity across sequential stages can have important consequences on morphology and life history traits such as developmental and growth rates. However, previous research in amphibians and other ectothermic vertebrates suggests that some morphological traits are generally insensitive to environmental inductions. We conducted a literature survey to examine the allometric responses in relative hind leg length and head shape of post-metamorphic anuran amphibians to induced environmental (temperature, resource level, predation and desiccation risk) variation operating during the larval phase in 44 studies using 19 species. To estimate and compare plastic responses across studies, we employed both an index of plasticity and effect sizes from a meta-analysis. We found contrasting trait responses to different environmental cues. Higher temperatures increased development more than growth rate and induced smaller heads but not overall shifts in hind leg length. In contrast, an increment in resource availability increased growth more than development, with a parallel increase in hind leg length but no change in head shape. Increases in predation risk decreased both development and growth rates and slightly reduced relative hind leg length, but there was no change in head shape. Pond desiccation induced quick development and low growth rates, with no changes in morphology. Across environments, both hind leg and head shape plasticity were positively correlated with growth rate plasticity. However, plasticity of developmental rate was only correlated with head shape plasticity. Overall, these results suggest that environmental trends predicted by global warming projections, such as increasing pond temperature and accelerating pond desiccation, will significantly influence hind leg and head morphology in metamorphic frogs, which may affect performance and, ultimately, fitness.
\end{abstract}

KEY WORDS: Morphology $\cdot$ Plasticity $\cdot$ Temperature $\cdot$ Resources $\cdot$ Pond desiccation $\cdot$ Predation risk Meta-analysis · Global warming

\section{INTRODUCTION}

Environmentally induced variation in body shape occurs in many taxa, and phenotypic plasticity in mor- phology has been found in response to several environmental factors such as diet (Wimberger 1992, Thompson 1999), temperature (de Jong et al. 2010, this Special, Trotta et al. 2010, this Special) and resource 
allocation (Nijhout \& Emlen 1998, Stern \& Emlen 1999, Canale \& Henry 2010, this Special). However, previous research on amphibians and other ectothermic vertebrates has suggested that size-independent metric shapes are generally insensitive to environmental induction (Arnold \& Peterson 1989, Blouin \& Loeb 1991, Forsman 1996, Blouin \& Brown 2000).

Development is a branching process in which undifferentiated precursor tissues may determine different phenotypes occurring later. Therefore, environmental influence on phenotypes may be especially relevant when this happens at early stages of the ontogeny (e.g. Lindström 1999). This may be of particular interest in animals with complex life cycles, as in most invertebrates and amphibians, where environmental induction during the embryo, larval or pupal stage can have strong effects on morphology after metamorphosis (Emerson 1986, Giménez 2006).

In amphibians, 4 major ecological factors, commonly encountered during the larval stage, can drastically affect metamorphic traits: temperature, trophic resources (via food availability or larval competition), habitat impermanence (via desiccation of temporary ponds, the common breeding environment for most amphibian species) and predator pressure (via behavioural trade-offs between growth and activity) (Alford 1999, Bruce 2005). Global warming will result in a general rise in pond temperatures, thus resulting in shorter pond durations during dry years (McMenamin et al. 2008), but it will also affect the rainfall regimes and environmental predictability across the globe. An increase in the frequency of severe droughts may also affect biotic interactions, presumably via a combined increase in both resource competition and predation. Therefore, climatic change is likely to affect all the main ecological factors affecting amphibian plasticity at metamorphosis.

Much of the research on amphibian developmental plasticity has concentrated on the effects of environmental induction on size and on time to metamorphosis (Wells 2007). Only recently have studies reported on the allometric (size-independent) shifts in hind leg length and head shape to varying growth conditions during the larval stages (Tejedo et al. 2000a, Relyea 2001, Van Buskirk \& Saxer 2001, Gomez-Mestre \& Buchholz 2006, Nicieza et al. 2006, Richter-Boix et al. 2006a, Orizaola \& Laurila 2009), which are partly due to allometric differences in the relative growth rates of the body and either hind leg or head (Emerson 1986, Emerson et al. 1988). In frogs, hind leg length and head shape are well-suited traits for analysing environmental effects on morphological variation since both traits have clear and testable morphofunctional implications. Relatively longer hind legs increase jumping performance (Emerson 1978, Zug 1978, Tejedo et al. 2000a,b, Gomes et al. 2009), and rapid adaptive coevolution between hind leg length and rate of movement has been suggested in the invasive toad Rhinella marina (Phillips et al. 2006). In addition, wider skulls and longer jaws may facilitate the intake of larger prey (Emerson 1985, Emerson \& Bramble 1993).

To predict the environmental outcome of climatic change, especially on low dispersal organisms such as amphibians, it is necessary to assess the magnitude and direction of plasticity in fitness-related traits in response to different environmental factors, and the potential of populations to evolve (Parmesan 2006, Chown et al. 2010, this Special). Current results in amphibians have revealed contrasting patterns in morphological inductions between different environmental factors. For instance, although increase in temperature and resource availability is predicted to boost both developmental and growth rates, their effects on hind leg length appear to be the opposite: longer legs when tadpoles are raised with increased resources (Emerson 1986, Tejedo et al. 2000a) and shorter legs when grown at higher temperatures (Gomez-Mestre \& Buchholz 2006). Therefore, it is currently difficult to establish a general pattern of how the larval environment affects morphological plasticity at metamorphosis.

In the present study we used meta-analytic techniques to describe the magnitude and direction of plasticity in hind leg length and head shape of postmetamorphic juvenile frogs induced by the 4 principal ecological factors operating during the larval phase: temperature, desiccation risk, resource availability and predation risk. All these factors will presumably be affected by global climate warming.

\section{METHODS}

\subsection{Data}

We examined a total of 44 experiments to test whether variation in these 4 environmental factors determine the allometric response in morphological shape after metamorphosis in frogs. We considered information for 19 different taxa (including the klepton Pelophylax kl. esculenta; see Table S1 in Supplement 1, see www.int-res.com/articles/suppl/c043p031_supp. pdf) reported in 11 published studies (24 experiments) between 1991 and 2009 and 10 unpublished studies carried out between 1995 and 2007 (20 experiments). All these studies, covering 20 mesocosms and 24 laboratory experiments, manipulated environmental conditions the larvae experienced. Resource availability (17 experiments), temperature (11 experiments), nonlethal predation risk (11 experiments), and pond desiccation risk ( 5 experiments) are known agents imposing 
substantial effects on larval growth and development in amphibians (Alford 1999). A total of 41 and 40 of the considered studies provided quantitative data on relative size of hind leg length/tibiofibula length and head width $(\mathrm{mm})$, respectively, together with information on time to (d) and size at metamorphosis (g) as well as larval growth rates $\left(\mathrm{g} \mathrm{d}^{-1}\right)$ (see Table $\left.\mathrm{S} 1\right)$.

We estimated adjusted mean differences in morphology between environments by using analysis of covariance (GLM module, STATISTICA 8.0, Statsoft). Body mass $\left(\ln\right.$ mass $\left.^{1 / 3}\right)(\mathrm{g})$ was used as a covariate for most of the studies. However, in Scaphiopus holbrooki, Spea mutiplicata, Spea intermontana and Pelobates cultripes (Gomez-Mestre \& Buchholz 2006, I. Gomez-Mestre \& D. R. Buchholz unpubl. data), Hyla cinerea (Blouin \& Loeb 1991) and Rana cascadae (Blouin \& Brown 2000), snout-vent length (SVL) (mm) was employed as covariate, and the first principal component (PC1) was used as a covariate in Discoglossus galganoi (Nicieza et al. 2006). The environment-body size interaction term was included in the model to test for heterogeneity of slopes. Initial analyses showed that, in most cases, this interaction was not significant ( $p>0.25)$. Thus the treatment term tested whether frogs raised in contrasting environments differed in size-independent shape. In some mesocosm experiments (source no. 4, 5, 10, 15, 16 and 17 in Table S1), individual responses were analysed and a mixed model was fitted, treating environment as a fixed factor and tank as a random variable nested within environments.

We were also interested in analysing the dependence of post-metamorphic shape on larval developmental and growth rates across species and experiments. Thus we considered developmental time as the time elapsed from the start of larval feeding phase (Gosner stage 25; Gosner 1960) to metamorphic climax with foreleg protrusion (Gosner stage 42). Size at metamorphosis was estimated as mass at metamorphosis after full tail resorption (Gosner stage 46), mass at Gosner stage 42 (Capellán \& Nicieza 2007) or SVL (Blouin \& Loeb 1991, Gomez-Mestre \& Buchholz 2006, I. Gomez-Mestre \& D. R. Buchholz unpubl. data). Growth rate $\left(\mathrm{g} \mathrm{d}^{-1}\right)$ was estimated as body size at metamorphosis divided by developmental time.

\subsection{Analyses}

To estimate and compare plastic responses across studies, we employed both an index of plasticity providing the change in percent, and effect sizes derived from a meta-analysis (Rosenberg et al. 2000). To estimate the index of plasticity, we first removed the differences between mean size-adjusted hind leg length and head width, and mean time and size to meta- morphosis and growth rates, at low temperature or resource level or at no desiccation or predation risk treatments (low treatments) by setting these variables to $100 \%$ (i.e. hind leg length low $=100$ ). Subsequently, we expressed the same variables at the high temperature or resource level or at predation or desiccation risk treatments (high treatments) as a fraction of this total, and plasticity was estimated as the difference between mean traits under high and low environmental conditions (plasticity hind leg length $=[$ (hind leg length high $/$ hind leg length low $)-1] \times 100$ ). Since this value of plasticity represents a dimensionless estimate of relative change, it can be used to compare different traits and experiments. Positive values of plasticity indicate that the trait increases in the high treatments, whereas a negative value indicates that the increase occurred in the low treatments. Plasticity index of either relative hind leg length or head width between different environmental factors were considered significant when reported in original paper or unpublished data.

In addition, we estimated the magnitude of plasticity in morphological and life history traits by parallel analyses conducted with effect sizes from a metaanalysis (Metawin 2.1, Rosenberg et al. 2000). Hyla versicolor and $H$. cinerea were excluded from some of the analyses because lack of information on sample sizes and standard errors prevented us from estimating effect sizes. The magnitude of the overall effect size is generally interpreted as small if Hedges' $d=0.2$, medium if $d=0.5$, large if $d=0.8$ and very large if $d>$ 1.0 (Cohen 1969). Effect sizes were considered significant if $95 \%$ confidence intervals did not overlap with zero.

The associations between plasticity estimates in hind leg length and head shape with developmental time, mass and growth rate plasticities were analyzed using Pearson's correlation and multiple regression analyses to tease apart the partial contributions of plasticity in developmental or growth rates to morphological plasticity. All the analyses were performed using STATISTICA 8.0 (Statsoft).

\section{RESULTS}

Ecological factors acting during the larval phase induced strong changes in larval life history traits in anuran amphibians (Table 1, Fig. 1). Increasing resource levels and temperature strongly accelerated both larval development and growth rates. However, we found contrasting trait responses to different environmental cues. Higher temperatures increased development more than growth rates, whereas an increment in resource availability resulted in greater enhancement of growth than development. An increase in 


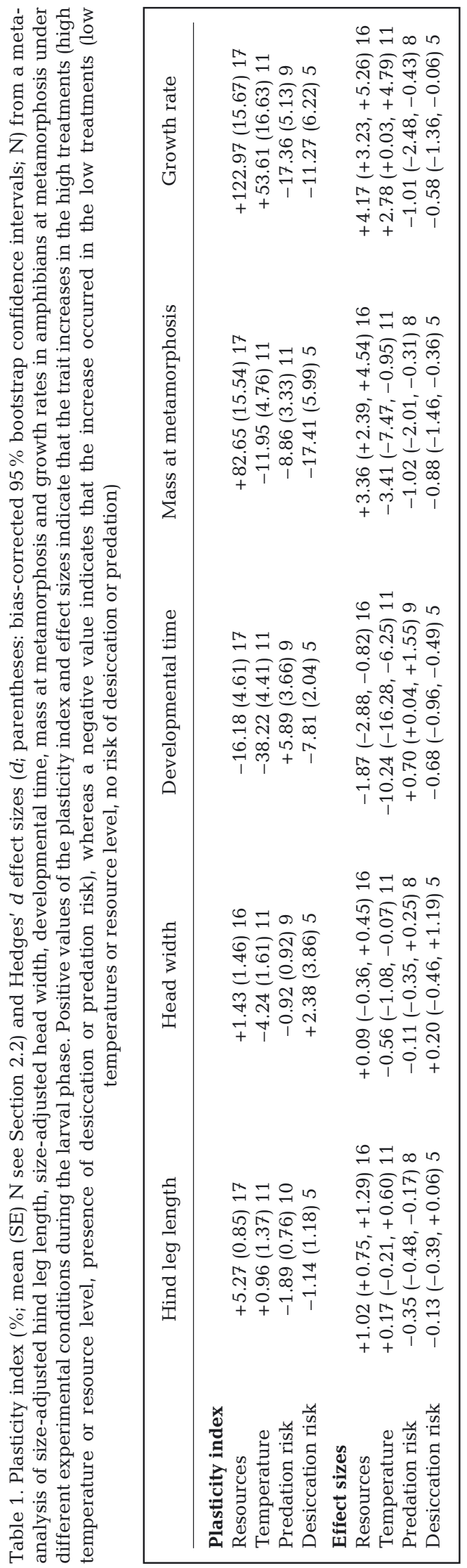

predation risk induced a small decrease in both development and growth rates, and pond desiccation increased developmental rate and reduced growth rate slightly. Mass at metamorphosis responded differentially depending on the ecological factor, with larger size when resources are plenty but smaller size with increases in temperature, predation or pond desiccation risk.

Larval environmental conditions affected the morphology of anurans at metamorphosis (Table 1, Fig. 1). For hind leg length, 32 of 43 studies $(74.4 \%)$ reported significant results, whereas only 24 of 41 studies $(58.5 \%)$ reported significant allometry in head shape (test of comparison between proportions, $p=0.126$, see Table S1). Most of the experiments found that allometric plasticity in morphology was low or moderate for both traits (hind leg, plasticity index range $=-5.6$ to $+10.3 \%$, Hedges' $d$ range $=-0.64$ to +2.63 ; head, plasticity index range $=-13.3$ to $+17.3 \%$, Hedges' $d$ range $=-2.12$ to $+2.04 ;$ Table S1). Resource availability and the presence of non-lethal predators induced the strongest changes in hind leg length by either elongating hind legs with increasing resource levels or shortening them with predation risk (Table 1, Fig. 1). Head shape allometry was only affected by temperature, implying a reduction in head size with increasing temperatures (Table 1, Fig. 1).

Hind legs were relatively longer when either growth rate or mass at metamorphosis was environmentally enhanced $(\mathrm{r}=0.52, \mathrm{p}=0.0005, \mathrm{~N}=41$; Fig. $2 \mathrm{a}$; $\mathrm{r}=$ $0.52, \mathrm{p}=0.0004, \mathrm{~N}=43$, respectively). However, there was no significant relationship between plasticity in hind leg length and plasticity in developmental time ( $\mathrm{r}=-0.20, \mathrm{p}=0.20, \mathrm{~N}=41$; Fig. 2b). Allometric changes in head width covaried positively with growth rate $(r=0.35, p=0.027, N=40$; Fig. $3 a)$ and mass at metamorphosis $(r=0.53, p=0.0003, N=41)$, and also with developmental time, although this result was marginally non-significant $(\mathrm{r}=0.29, \mathrm{p}=$ 0.06, $\mathrm{N}=40$; Fig. 3b).

Time to metamorphosis and growth rate plasticity were negatively correlated $(\mathrm{r}=-0.44, \mathrm{p}=0.0036, \mathrm{~N}=$ 42). Hind leg length plasticity was explained by the partial contribution of growth rate plasticity after controlling for variation in developmental rate plasticity (Beta $=0.502, \mathrm{p}=0.0007)$, but the partial contribution of developmental rate was not significant (Beta = $0.211, \mathrm{p}=0.129$ ). Head width plasticity was explained by partial contributions of both growth rate $($ Beta $=$ 0.593, $\mathrm{p}=0.0002)$ and developmental rate $($ Beta $=$ 0.552, $\mathrm{p}=0.0005)$. Parallel analyses conducted with effect sizes from the meta-analysis (Metawin 2.1, Rosenberg et al. 2000) provided similar trends to those found with our plasticity index and are not shown in detail here. 

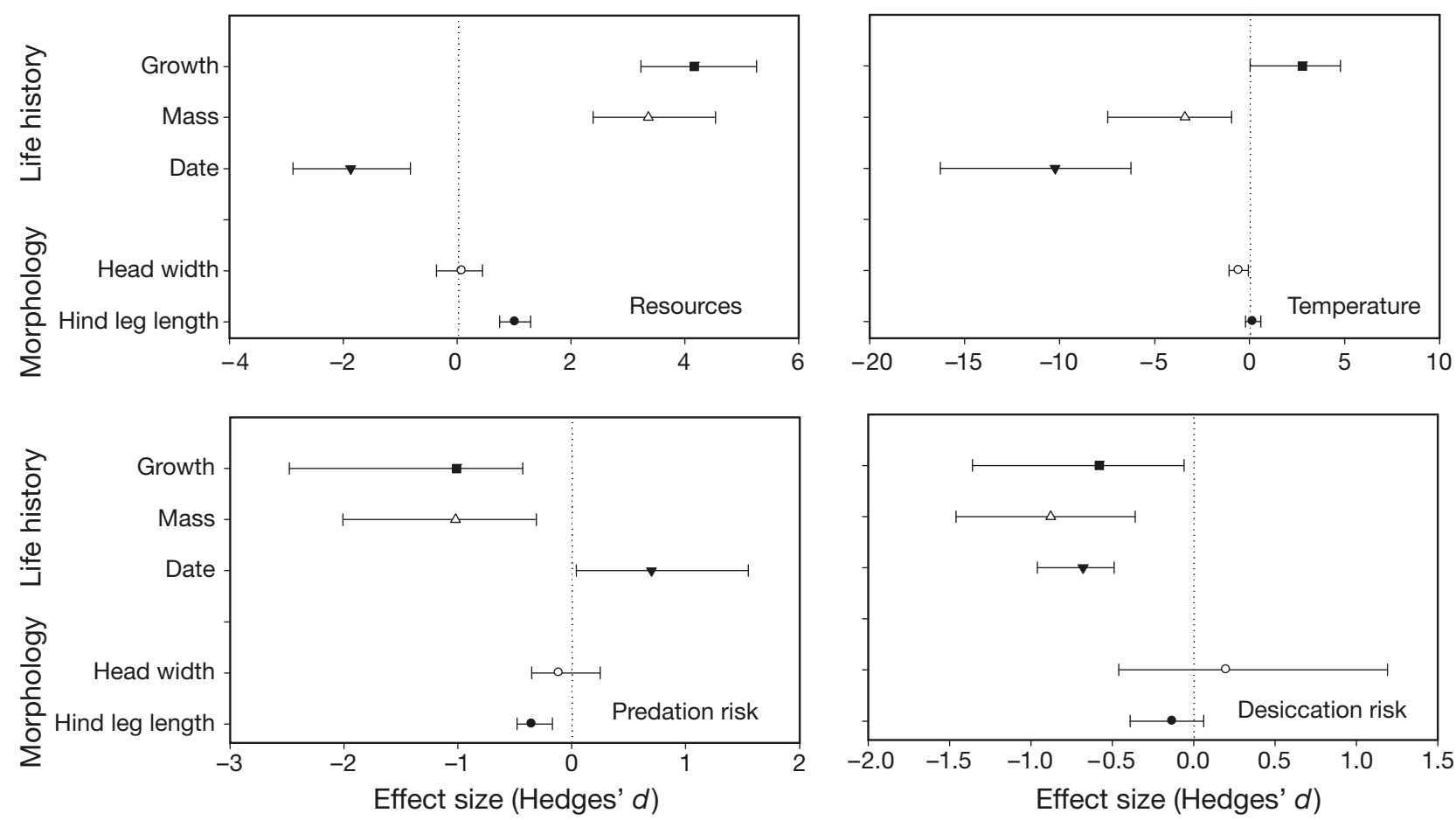

Fig. 1. Mean effect sizes (Hedges' $d$ ) and bias-corrected bootstrapped $95 \%$ confidence intervals for morphological (size-adjusted hind leg length and head width) and life history traits (date of metamorphosis, mass at metamorphosis and growth rates) in amphibians at metamorphosis under different experimental conditions during the larval phase. Effects are statistically significant $(\mathrm{p}<0.05)$ if confidence intervals excluded zero. Positive values of $d$ : trait increases in the high treatments (high temperature or resource level, presence of desiccation or predation risk); negative value: increase occurred in the low treatments (low temperatures or resource level, no risk of desiccation or predation)
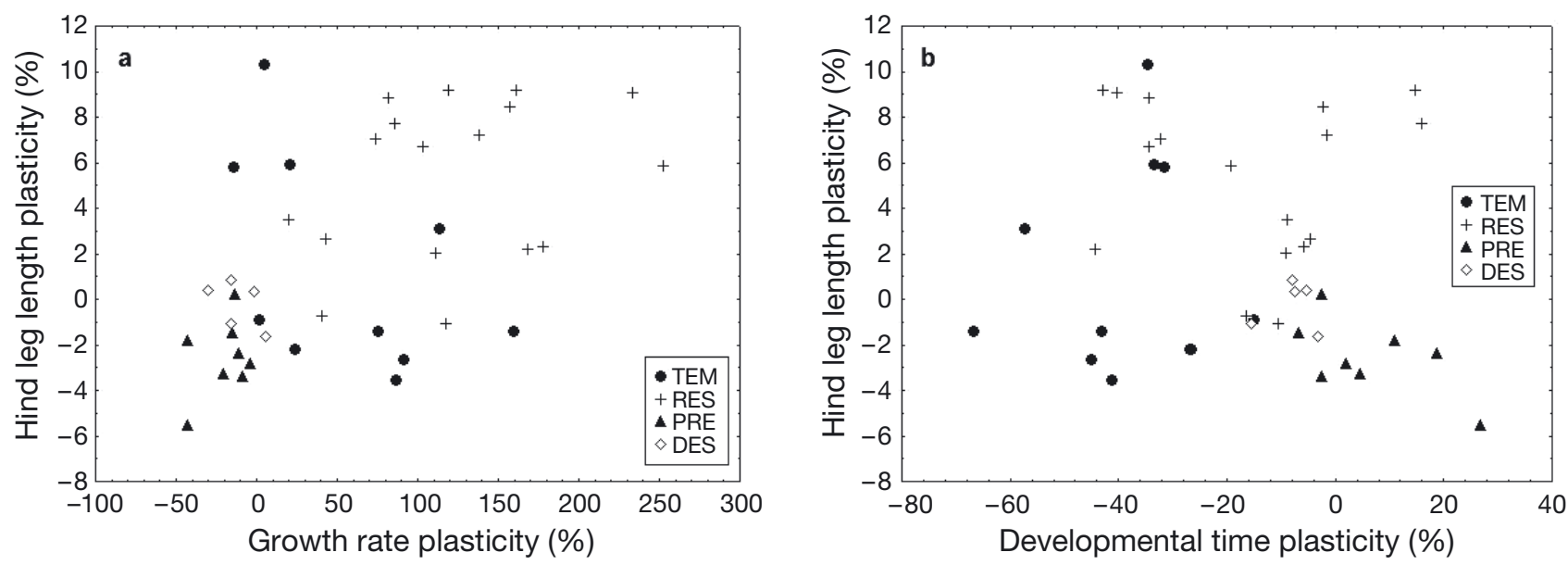

Fig. 2. Correlation between size-adjusted hind leg length plasticity and plasticity in either (a) growth rate $(r=0.52, p=0.0005, N=$ 41 , Section 3) or (b) developmental time ( $\mathrm{r}=-0.20, \mathrm{p}=0.20, \mathrm{~N}=41$, Section 3$)$ in amphibians at metamorphosis under different experimental conditions during the larval phase. RES: resource level; TEM: temperature; PRE: predation risk, DES: desiccation risk

\section{DISCUSSION}

In anurans, environmental variation in the aquatic larval habitat promotes shifts in growth and differentiation rates that influence morphological shape at metamorphosis. This is an indication that ecological condi- tions determine allometric growth between body size, hind legs and head throughout development (Emerson 1986). The environmentally induced plasticity in morphological shape found in anurans via alteration of growth and developmental rates may be also widespread in other organisms (e.g. Strathmann et al. 1992, 

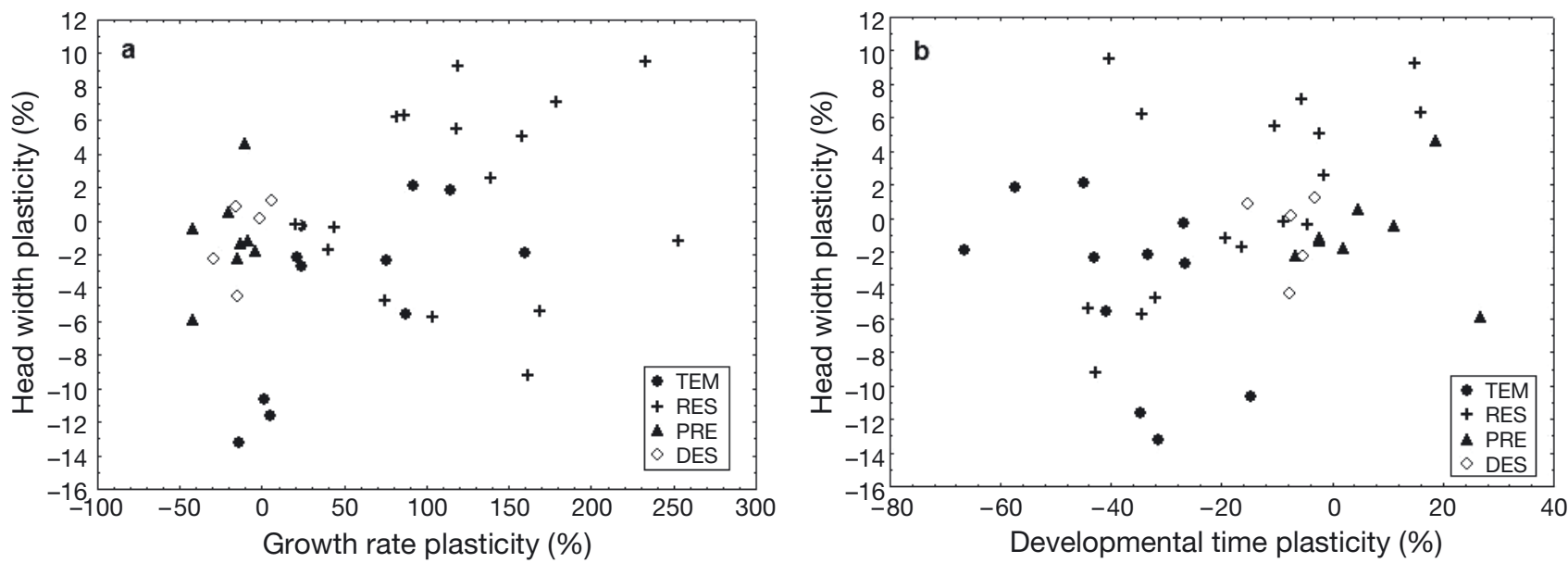

Fig. 3. Correlation between size-adjusted head width plasticity and plasticity in either (a) growth rate $(r=0.35, p=0.027, N=40$, Section 3) or (b) developmental time ( $r=0.29, \mathrm{p}=0.06, \mathrm{~N}=40$, Section 3$)$ in amphibians at metamorphosis under different experimental conditions during the larval phase: RES: resource level; TEM: temperature; PRE: predation risk, DES: desiccation risk

Elphick \& Shine 1998, Zijlstra et al. 2003, Moriuchi \& Winn 2005).

The increase in resource availability induced a consistent response with elongation of hind legs with the exception of Discoglossus galganoi, which exhibited a slight non-significant reduction (Nicieza et al. 2006). However, the pattern of increased resource induction on head shape appears inconsistent across species, as some species exhibited wider (e.g. Rana species, Agalychnis callidryas and D. galganoi) and others narrower heads (Pelobates cultripes and Pelodytes ibericus; see Table S1). The morphological pattern observed at reduced resource levels (i.e. metamorphs with shorter hind legs and wider heads in some species) seems to mirror less developed morphology, as tadpoles approaching metamorphosis tend to elongate the hind legs and narrow the head (Sokol 1984, Hall et al. 1997, Cannatella 1999). A similar trend was found when larvae develop under predation risk (see below). Hence stressful conditions operating during larval stages (lower resource levels or predation risk) seem to promote a faster whole-body developmental rate that allows larvae to escape from a poor growing environment at the cost of incomplete development of some body parts (e.g. hind legs).

Higher temperature during the larval phase induced a significant reduction in metamorph head width. Results across species appear strongly consistent, with the exception of Rana cascadae and Xenopus laevis, which showed increased head size; however, both plasticity values were non-significant (Blouin \& Brown 2000, I. Gomez-Mestre et al. unpubl. data). A similar reduction in head width was found in Xenopus laevis when temperature was increased only during the metamorphic climax (Walsh et al. 2008), which agrees with the general trend of head reduction at higher developmental tem- peratures. These results are similar to those found in other ectotherms, showing reduced size of several morphological traits, such as the wings, thorax and head under higher developmental temperatures (French et al. 1998, Ottenheim \& Volmer 1999, Stevens 2004, Santos et al. 2006, Trotta et al. 2010). In amphibians, a reduction of head size may have some negative consequences on individual performance, since most species are gape-limited predators and reduced head size may decrease ingestion capability in juveniles and reduce the ranges in size and type of potential prey (Emerson \& Bramble 1993, Maglia 1996). Interestingly, increasing temperature did not induce a response in hind leg length with an effect size not different from zero. Although developmental time was clearly reduced and growth rate was enhanced, an expected hind leg elongation similar to that found with increasing resources was only found for ranid frogs (Rana cascadae, Blouin \& Brown 2000; and R. lessonae, Orizaola \& Laurila 2009), whereas a shortening in hind legs was found for the rest of species. This contrasting pattern may reflect a phylogenetic signal, although the small sample size (6 species) precludes any power in the statistical analysis of phylogenetic autocorrelation (Abouheif 1999). Therefore, more information is required to depict a general trend of temperature effect on hind legs in amphibians and its proximate mechanisms.

Exposure to predation risk during larval development promoted changes in allometric shape of metamorphs. High predation risk generally induced shorter relative hind legs. In the present study, the data are highly consistent, with the exception of the longer hind legs of Rana sylvatica frogs emerging from the predator treatment (Relyea 2001) (see Table S1, Fig. 1).

Desiccation risk induced a plastic acceleration of developmental rate, with a parallel decline in growth 
rates and size at metamorphosis. Pond desiccation poses a strong time constraint for development of larval amphibians. The increase in developmental rate and reduction in growth rate is the common response to pond desiccation expressed by larval anurans both at the intra- and interspecific level (Brady \& Griffiths 2000, Leips et al. 2000, Merilä et al. 2004, Richter-Boix et al. 2006b, A. Richter-Boix et al. unpubl. data). The consequences of pond desiccation on allometric shape seem to be a decrease in relative hind legs, although this effect was not significant, probably due to the small sample size (5 contrasts for 3 species). However, we propose that this trend is general, as other studies have reported shorter hind legs under pond desiccation risk, e.g. in Scaphiopus couchii (Newman 1989) and Rhinella spinulosa (Márquez-García et al. 2009).

Plasticity of hind leg length and head shape was of relatively low or moderate magnitude, especially if compared with plasticity in development, growth rate or mass at metamorphosis. Therefore, the direct consequences for fitness will require further testing. Interspecific comparisons have suggested that an increase of $\geq 10 \%$ in leg length is needed to have a substantial influence on locomotion (Zug 1972, Emerson 1978). In fact, several recent morphofunctional analyses, where the relative hind leg lengths were experimentally manipulated, have revealed that a small (1 to $2 \%$ ) increase of relative hind leg length did not result in significantly enhanced locomotor performance (Van Buskirk \& Saxer 2001, Richter-Boix et al. 2006a; see Table S1). In contrast, a larger increase of relative hind leg length in Pelophylax kl. esculenta (7.2\%) and Pelodytes punctatus (8.8\%) under high resource availability (Table S1) determined a concomitant increase of 32.4 and $34 \%$ in size-adjusted maximum jumping distance, respectively (Tejedo et al. 2000a, M. Tejedo et al. unpubl. data). Similarly, increases in relative leg length (5.8 to $10.3 \%$ ) in warm larval environments in Rana lessonae populations increased relative jumping performance by 15.1 to $29.4 \%$ in 2 out of 3 studied populations (Orizaola \& Laurila 2009). These latter studies suggest that environmentally induced allometries in hind leg length may have important consequences on performance, once a minimum amount of hind leg elongation is attained. Therefore, we can expect that any small advantage may be selectively important considering the intense predation that amphibians suffer, especially during metamorphosis and early juvenile life (Arnold \& Wassersug 1978). Recent studies have found that population variation in relative hind leg length correlates with locomotor performance (Ficetola \& de Bernadi 2006, Phillips et al. 2006). The role that plasticity, induced during the larval phase, may play in driving this adaptive divergence (e.g. through genetic assimilation) deserves more research (Gomez-Mestre \& Buchholz 2006, Wund et al. 2008).
In general, plasticity of shape in juvenile frogs across environments is dependent on variation in either developmental and/or growth rate plasticities. Environments promoting higher larval growth rates produce juvenile frogs with relatively longer hind legs and wider heads. Poor growing environments, in contrast, will produce stumpy juveniles with relatively poor jumping performance. However, the pattern of integration of developmental rates with post-metamorphic morphology differs between traits. Environmentally induced variation in developmental rates translated to changes in relative head size, but not relative hind leg length. The variation in elongation of hind leg length at metamorphosis was only affected by variation in growth rates. This conclusion agrees with an experiment designed to tease apart both growth and developmental rate by altering larval growth rates while keeping the pace of developmental rate unchanged (M. Tejedo et al. unpubl. data). The results revealed that the treatment where larval growth was diminished at late pre-metamorphosis (33-34 Gosner stage) resulted in similar developmental rates as in the control but, in contrast to expectations, overall size and relative hind legs were smaller than the control. As a result, and coincident with our analyses, final hind leg shape was more dependent on variation in growth rates than variation in developmental rate.

A final consideration is the persistence of the plasticity. i.e. whether the level of plasticity found in hind leg length and head width at metamorphosis can be relatively transient and disappear during early juvenile growth. In holometabolous insects, the morphological effects of larval and pupae environments on adults are fixed (Boggs 1981). However, environmentally induced changes in amphibians may not be permanent and concomitant to their fitness consequences. In reptiles, duration of thermally induced allometries is short (Shine et al. 1997, Elphick \& Shine 1998). This may also be the general pattern in amphibians, as found in 2 pelodytids (Pelodytes punctatus and Pelodytes ibericus; M. Tejedo et al. unpubl. data) and 1 pelobatid frog (Pelobates cultripes; M. Tejedo \& I. Gomez-Mestre unpubl. data). Consequently, compensatory growth processes can result in a more canalised phenotype during the adult stage (Emerson 1986). Thus, in terms of fitness, the biological significance of the developmental plasticity for hind leg shape found at metamorphosis may be time-limited.

Global warming will probably increase both air temperature and decrease rainfall amount in many areas of the world (IPCC 2007), which will indirectly determine increasing pond desiccation rates. As our results suggest, increased temperature and pond desiccation risk during the anuran larval phase can be predicted to produce smaller-headed and possibly shorter-legged frogs. However, climate change is also going to affect resource availability, primary production, competition 
and predation risk in unpredictable ways. These effects are going to be highly system-specific; therefore, the effects of global warming on froglet morphology and fitness are difficult to predict.

Acknowledgements. We acknowledge the ConGen and ThermAdapt programmes (funded by the European Science Foundation) for organizing the workshop 'Evolutionary and Physiological Adaptation to Climate Induced Environmental Changes' held in Białowieża, Poland, 29 June-1 July 2009. Thanks to M. Calduch, J. M. de Alba and C. Gómez who helped with the measurements of morphology of metamorphs, and E. Dahl for useful suggestions and linguistic revision. This research was funded by projects PB96-0861 and CGL2009-12767-C02-02 to M.T. F.M. was supported by a doctoral grant contract funded by the project CGL200401872/BOS to M.T. C.P. was supported by grants from the Danish Natural Sciences Research Council (21-01-0526 and 21-03-0125) and the Marie Curie Fellowship of the European Community Host Development program under contract nos. HPMD-CT-2000-00009, REN2001-2647/GLO and MMA-862003 to A.G.N.

\section{LITERATURE CITED}

Abouheif E (1999) A method for testing the assumption of phylogenetic independence in comparative data. Evol Ecol Res 1:895-909

Alford RA (1999) Ecology: resource use, competition, and predation. In: McDiarmid RW, Altig R (eds) Tadpoles: the biology of anuran larvae. University of Chicago Press, Chicago, IL, p 240-278

Arnold SJ, Peterson CR (1989) A test for temperature effects on the ontogeny of shape in the garter snake Thamnophis sirtalis. Physiol Zool 62:1316-1333

Arnold EN, Wassersug R (1978) Differential predation on metamorphic anurans by garter snakes (Thamnophis): social behavior as a possible defense. Ecology 59:1014-1022

Blouin MS, Brown TS (2000) Effects of temperature-induced variation in anuran larval growth rate on head width and leg length at metamorphosis. Oecologia 125:358-361

Blouin MS, Loeb LG (1991) Effects of environmentally induced development-rate variation on head and limb morphology in the green tree frog, Hyla cinerea. Am Nat 138:717-728

Boggs CL (1981) Nutritional and life-history determinants of resource allocation in holometabolous insects. Am Nat 117: 692-709

Brady LD, Griffiths RA (2000) Developmental responses to pond desiccation in tadpoles of the British anuran amphibians (Bufo bufo, B. calamita and Rana temporaria). J Zool 252:61-69

Bruce RC (2005) Theory of complex life cycles: application in plethodontid salamanders. Herpetol Monogr 19:180-207

Canale CI, Henry PY (2010) Adaptive phenotypic plasticity and resilience of vertebrates to increasing climatic unpredictability. Clim Res 43:135-147

Cannatella D (1999) Architecture: cranial and axial musculoskeleton. In: McDiarmid RW, Altig R (eds) Tadpoles: the biology of anuran larvae. University of Chicago Press, Chicago, IL, p 52-91

Capellán E, Nicieza AG (2007) Non-equivalence of growth arrest induced by predation risk or food limitation: contextdependent compensatory growth in anuran tadpoles. J Anim Ecol 76:1026-1035

Chown SL, Hoffmann AA, Kristensen TN, Angilletta MJ Jr,
Stenseth NC, Pertoldi C (2010) Adapting to climate change: a perspective from evolutionary physiology. Clim Res 43: $3-15$

Cohen J (1969) Statistical power analysis for the behavioral sciences. Academic Press, New York

> de Jong MA, Kesbeke FMNH, Brakefield PM, Zwaan BJ (2010) Geographic variation in thermal plasticity of life history and wing pattern in Bicyclus anynana. Clim Res 43:91-102

- Elphick MJ, Shine R (1998) Longterm effects of incubation temperatures on the morphology and locomotor performance of hatchling lizards (Bassiana duperreyi, Scincidae). Biol J Linn Soc 63:429-447

Emerson SB (1978) Allometry and jumping in frogs: helping the Twain to meet. Evolution 32:551-564

Emerson SB (1985) Skull shape in frogs: correlations with diet. Herpetologica 41:177-188

- Emerson SB (1986) Heterochrony and frogs: the relationship of a life history trait to morphological form. Am Nat 127: 167-183

Emerson SB, Bramble DM (1993) Scaling, allometry, and skull design. In: Hanken J, Hall B (eds) The skull. University of Chicago Press, Chicago, IL, p 384-421

Emerson SB, Travis J, Blouin M (1988) Evaluating a hypothesis about heterochrony: larval life-history traits and juvenile hind-limb morphology in Hyla crucifer. Evolution 42:68-78

> Ficetola GF, De Bernardi F (2006) Trade-off between larval development rate and post-metamorphic traits in the frog Rana latastei. Evol Ecol 20:143-158

Forsman A (1996) An experimental test for food effects on head size allometry in juvenile snakes. Evolution 50:2536-2542

French V, Feast M, Partridge L (1998) Body size and cell size in Drosophila: the developmental response to temperature. J Insect Physiol 44:1081-1089

> Giménez L (2006) Phenotypic links in complex life cycles: conclusions from studies with decapod crustaceans. Integr Comp Biol 46:615-622

> Gomes FR, Rezende EL, Grizante MB, Navas CA (2009) The evolution of jumping performance in anurans: morphological correlates and ecological implications. J Evol Biol 22:1088-1097

> Gomez-Mestre I, Buchholz DR (2006) Developmental plasticity mirrors differences among taxa in spadefoot toads linking plasticity and diversity. Proc Natl Acad Sci USA 103: 19021-19026

Gosner KL (1960) A simplified table for staging anuran embryos and larvae with notes on identification. Herpetologica 16:183-190

> Hall JA Jr, Larsen JH, Fitzner RE (1997) Postembryonic ontogeny of the spadefoot toad, Scaphiopus intermontanus (Anura: Pelobatidae): external morphology. Herpetol Monogr 11:124-178

IPCC (2007) Climate change 2007: synthesis report. Contribution of Working Groups I, II and III to the Fourth Assessment Report of the Intergovernmental Panel on Climate Change. Cambridge University Press, Cambridge

> Leips J, McManus MG, Travis J (2000) Response of treefrog larvae to drying ponds: comparing temporary and permanent pond breeders. Ecology 81:2997-3008

> Lindström J (1999) Early development and fitness in birds and mammals. Trends Ecol Evol 14:343-348

- Maglia AM (1996) Ontogeny and feeding ecology of the red-backed salamander, Plethodon cinereus. Copeia 1996: $576-586$

Márquez-García M, Correa-Solis M, Sallaberry M, Méndez MA (2009) Effects of pond drying on morphological and life-history traits in the anuran Rhinella spinulosa (Anura: Bufonidae). Evol Ecol Res 11:803-815

McMenamin SK, Hadly EA, Wright CK (2008) Climatic change 
and wetland desiccation cause amphibian decline in Yellowstone National Park. Proc Natl Acad Sci USA 105: 16988-16993

Merilä J, Laurila A, Lindgren B (2004) Variation in the degree and costs of adaptive phenotypic plasticity among Rana temporaria populations. J Evol Biol 17:1132-1140

Moriuchi KS, Winn AA (2005) Relationships among growth, development and plastic response to environment quality in a perennial plant. New Phytol 166:149-158

Newman RA (1989) Developmental plasticity of Scaphiopus couchii tadpoles in an unpredictable environment. Ecology 70:1775-1787

> Nicieza AG, Alvarez D, Atienza EMS (2006) Delayed effects of larval predation risk and food quality on anuran juvenile performance. J Evol Biol 19:1092-1103

Nijhout HF, Emlen DJ (1998) Competition among body parts in the development and evolution of insect morphology. Proc Natl Acad Sci USA 95:3685-3689

Orizaola G, Laurila A (2009) Microgeographic variation in the effects of larval temperature environment on juvenile morphology and locomotion in the pool frog. J Zool 277:267-274

Ottenheim MM, Volmer AD (1999) Wing length plasticity in Eristalis arbustorum (Diptera: Syrphidae). Neth J Zool 49: $15-27$

Parmesan C (2006) Ecological and evolutionary responses to recent climate change. Annu Rev Ecol Evol Syst 37: 637-669

Phillips BL, Brown GP, Webb JK, Shine R (2006) Invasion and the evolution of speed in toads. Nature 439:803

Relyea RA (2001) The lasting effects of adaptive plasticity: predator-induced tadpoles become long-legged frogs. Ecology 82:1947-1955

Relyea RA, Hoverman JT (2003) The impact of larval predators and competitors on the morphology and fitness of juvenile treefrogs. Oecologia 134:596-604

Richter-Boix A, Llorente GA, Montori A (2006a) Effects of phenotypic plasticity on post-metamorphic traits during premetamorphic stages in the anuran Pelodytes punctatus. Evol Ecol Res 8:309-320

Richter-Boix A, Llorente GA, Montori A (2006b) A comparative analysis of the adaptive developmental plasticity hypothesis in six Mediterranean anuran species along a pond permanency gradient. Evol Ecol Res 8:1139-1154

Rosenberg MS, Adams DC, Gurevitch J (2000) MetaWin: statistical software for meta-analysis, Version 2. Sinauer Associates, Sunderland, MA

Santos M, Brites D, Laayouni H (2006) Thermal evolution of pre-adult life history traits, geometric size and shape, and developmental stability in Drosophila subobscura. J Evol Biol 19:2006-2021

Shine R, Elphick MJ, Harlow PS (1997) The influence of natural incubation environments on the phenotypic traits of hatchling lizards. Ecology 78:2559-2568

Sokol A (1984) Plasticity in the fine timing of metamorphosis

Submitted: April 6, 2010; Accepted: May 12, 2010 in tadpoles of the hylid frog, Litoria ewingi. Copeia 1984: 868-873

Stern DL, Emlen DJ (1999) The developmental basis for allometry in insects. Development 126:1091-1101

Stevens DJ (2004) Pupal development temperature alters adult phenotype in the speckled wood butterfly, Pararge aegeria. J Therm Biol 29:205-210

Strathmann RR, Fenaux L, Strathmann MF (1992) Heterochronic developmental plasticity in larval sea urchins and its implications for the evolution of nonfeeding larvae. Evolution 46:972-986

Tejedo M, Semlitsch RD, Hotz H (2000a) Covariation of morphology and jumping performance in newly metamorphosed water frogs: effects of larval growth history. Copeia 2000:448-458

Tejedo M, Semlitsch RD, Hotz H (2000b) Differential morphology and jumping performance of newly metamorphosed frogs of the hybridogenetic Rana esculenta complex. J Herpetol 34:201-210

Thompson DB (1999) Genotype-environment interaction and the ontogeny of diet-induced phenotypic plasticity in size and shape of Melanoplus femurrubrum (Orthoptera: Acrididae). J Evol Biol 12:38-48

Trotta V, Pertoldi C, Rudoy A, Manenti T, Cavicchi S, Guerra D (2010) Thermal plasticity of wing size and shape in Drosophila melanogaster, D. simulans and their hybrids. Clim Res 43:71-79

Van Buskirk J, Saxer G (2001) Delayed costs of an induced defense in tadpoles? Morphology, hopping, and development rate at metamorphosis. Evolution 55:821-829

Walsh PT, Downie JR, Monaghan P (2008) Temperature-mediated morphology changes during metamorphic climax in the African clawed frog, Xenopus laevis. J Therm Biol 33:244-249

Wells KD (2007) The ecology and behavior of amphibians. Chicago University Press, Chicago, IL

Wimberger PH (1992) Plasticity of fish body shape. The effects of diet, development, family and age in two species of Geophagus (Pisces: Cichlidae). Biol J Linn Soc 45:197-218

Wund MA, Baker JA, Clancy B, Justin L, Golub JL, Foster SA (2008) A test of the 'flexible stem' model of evolution: ancestral plasticity, genetic accommodation, and morphological divergence in the threespine stickleback radiation. Am Nat 172:449-462

Zijlstra WG, Steingenga MJ, Brakefield PM, Zwaan BJ (2003) Simultaneous selection on two fitness-related traits in the butterfly Bicyclus anyana. Evolution 57:1852-1862

Zug GR (1972) Anuran locomotion: structure and function. I. Preliminary observations on relation between jumping and osteometrics of appendicular and postaxial skeleton. Copeia 1972:613-624

Zug GR (1978) Anuran locomotion-structure and function. II. Jumping performance of semiaquatic, terrestrial, and arboreal frogs. Smithson Contrib Zool 276:1-31

Proofs received from author(s): July 22, 2010 